\title{
Recurrent Lupus nephritis in the Second Allograft of a Patient with Systemic Lupus erythematosus
}

\author{
J orge Isaac ${ }^{a}$ Fuad S. Shihab ${ }^{b}$ \\ ${ }^{a}$ Anatomical/Renal Pathology and b Division of Nephrology and Hypertension, University of Utah \\ Health Sciences Center and ARUP Laboratories, Salt Lake City, Utah, USA
}

\section{Key Words}

Allograft · Lupus · Recurrent

\begin{abstract}
Lupus glomerulonephritis is a common and serious complication of systemic lupus erythematosus (SLE) affecting up to $50 \%$ of lupus patients. Recurrent lupus nephritis is rare, complicating as low as $1 \%$ of the lupus transplant population according to some authors. However, it may be underreported with more realistic recurrent rates oscillating from 2.8 to $8.7 \%$. We report the case of a patient with SLE who lost her first allograft 4 years after transplantation with a diagnosis of de novo fibrillary glomerulopathy. She underwent a second renal transplantation and her renal function was stable for the past 5 years. She now presented with skin rash, arthralgias and positive lupus serologies. Her creatinine was slightly elevated and proteinuria was also noted. A renal biopsy performed revealed a recurrent focal proliferative lupus nephritis (WHO III). Retrospectively, we believe that her first allograft was also lost to recurrent lupus nephritis. This is a unique case of recurrent lupus nephritis in the second allograft of a patient with SLE.
\end{abstract}

Copyright $\odot 2002$ S. Karger AG, Basel

\section{Introduction}

Renal involvement is a common and serious complication of SLE, and lupus glomerulonephritis will affect up to $50 \%$ of SLE patients [1]. Approximately $10 \%$ of these patients will develop end stage renal disease, even with appropriate immunosuppressive treatment [2]. It is now well accepted that lupus patients are good candidates for renal transplantation [3]. Recurrent disease during the cyclosporine era has been shown to occur in $6.3 \%$ of cases after an average of 36 months after transplantation. Two of 73 cases of recurrent renal disease were secondary to SLE, and the risk of recurrence increased with length of graft survival ( $2.8 \%$ at 2 years, $9.8 \%$ at 5 years and up to $18.5 \%$ at 8 years) [4]. We report a case of recurrent focal proliferative lupus nephritis (WHO III), in the second allograft of a patient with SLE.

\section{Case Report}

We report the case of a 44-year-old female with end-stage renal disease secondary to SLE, who lost her first renal allograft, and now developed recurrent lupus nephritis in her second renal allograft. The patients native kidney biopsy revealed a diffuse proliferative lupus nephritis (WHO IV). She received a cadaveric kidney transplantation at the University of Utah for the first time in 1991. She lost her first allograft in 1995 and the renal biopsy at that time revealed a focal mesangialproliferative glomerulonephritis with fibrillary mesangial deposits by electron microscopy, and positive mesangial

\begin{tabular}{ll}
\hline KARGER & ( ) 2002 S. Karger AG, Basel \\
0028-2766/02/0924-0947\$18.50/0 \\
$\begin{array}{l}\text { Fax +4161306 12 34 } \\
\begin{array}{l}\text { E-Mail karger@karger.ch } \\
\text { www.karger.com }\end{array}\end{array}$ & $\begin{array}{l}\text { Accessible online at: } \\
\text { www.karger.com/journals/nef }\end{array}$
\end{tabular}

Jorge Isaac, MD

Department of Pathology/ARUP Laboratories, University of Utah, Health Sciences Center 50 N. Medical Drive. A-513

Salt Lake City UT 84132 (USA)

Tel. +1 801585 2540, Fax +1 801585 3831, E-Mail jorge.isaac@path.utah.edu 
immunofluorescence staining for IgG and C3. This biopsy was interpreted as de novo fibrillary glomerulopathy. She underwent a second cadaveric renal transplantation in 1996 and had stable renal function until June, 2001. She received induction OKT3 for the second time which she tolerated well. She had no evidence of antibody formation.

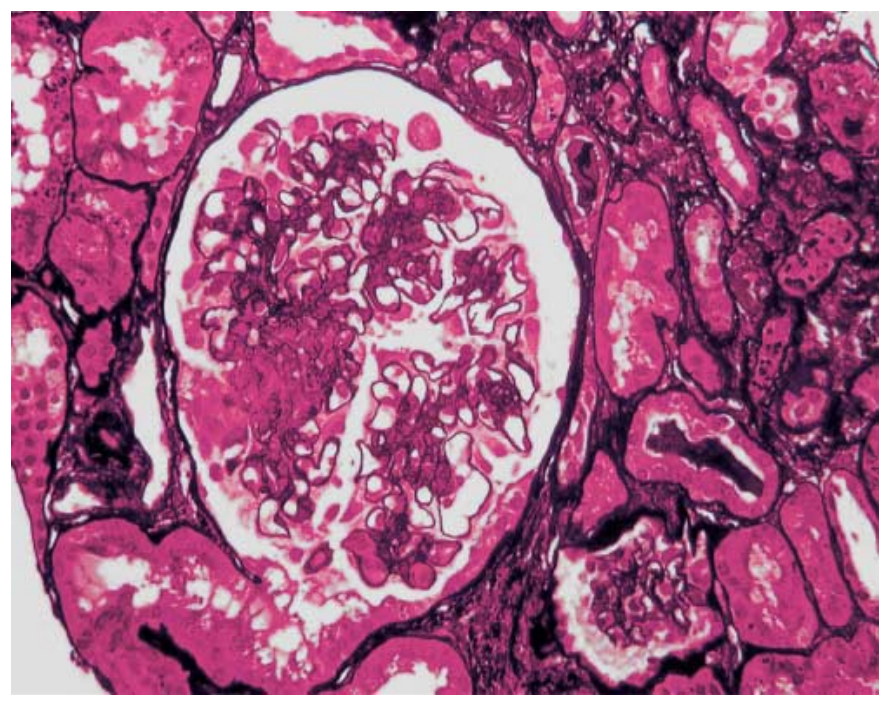

Fig. 1. Reactive parietal epithelial cells with associated focal collapse of peripheral loops, and segmental thickening of membranes with focal evidence of 'double contours'. Silver stain. $\times 20$.
Her maintenance immunosuppressive regimen included prednisone, azathioprine, and cyclosporine. She continued with stable renal function until 6/2001 when she presented with skin rash, arthralgias, mild proteinuria $(60 \mathrm{mg} / \mathrm{dl})$, low complement levels $(\mathrm{C} 3,49 \mathrm{mg} / \mathrm{dl}$, normal range between 88 and 201; C4, $6 \mathrm{mg} / \mathrm{dl}$, normal range between 10 and 40$)$, and slight increase in serum creatinine $(1.4 \mathrm{mg} / \mathrm{dl})$. Serologies revealed positive antinuclear antibody (ANA, IgG titer of 1:2,560, $>1: 160$ considered significant), and positive double strand anti-DNA antibodies (dsDNA Ab, IgG 1:80, <1:10 interpreted as negative). A renal biopsy was performed.

\section{Light Microscopy}

Twenty glomeruli were available for evaluation. The glomeruli showed subtle mesangial expansion by matrix and focally by borderline cellularity. Two glomeruli exhibited changes suggesting a focal and segmental membranoproliferative pattern. There was segmental thickening of peripheral membranes with focal evidence of 'double contour' appreciated with the silver stain (fig. 1). There was also focal and mild interstitial fibrosis (involving about $15 \%$ of the cortical aspect of the biopsy), confirmed with the trichrome stain.

\section{Immunofluorescence Studies}

There was positive mainly peripheral and granular immunofluorescence staining for $\operatorname{IgG}(1+), \operatorname{IgA}(2+), \operatorname{IgM}(2+), C 3(2+), C 1 \mathrm{q}$ $(1-2+)$, and kappa and lambda (1-2+ for each). The controls were adequate (fig. 2, left).

\section{Electron Microscopy}

Ultrastructurally, there was diffuse fusion of the foot processes of the visceral epithelial cells. The mesangium appeared segmentally expanded by matrix and focally by cells. The peripheral membranes
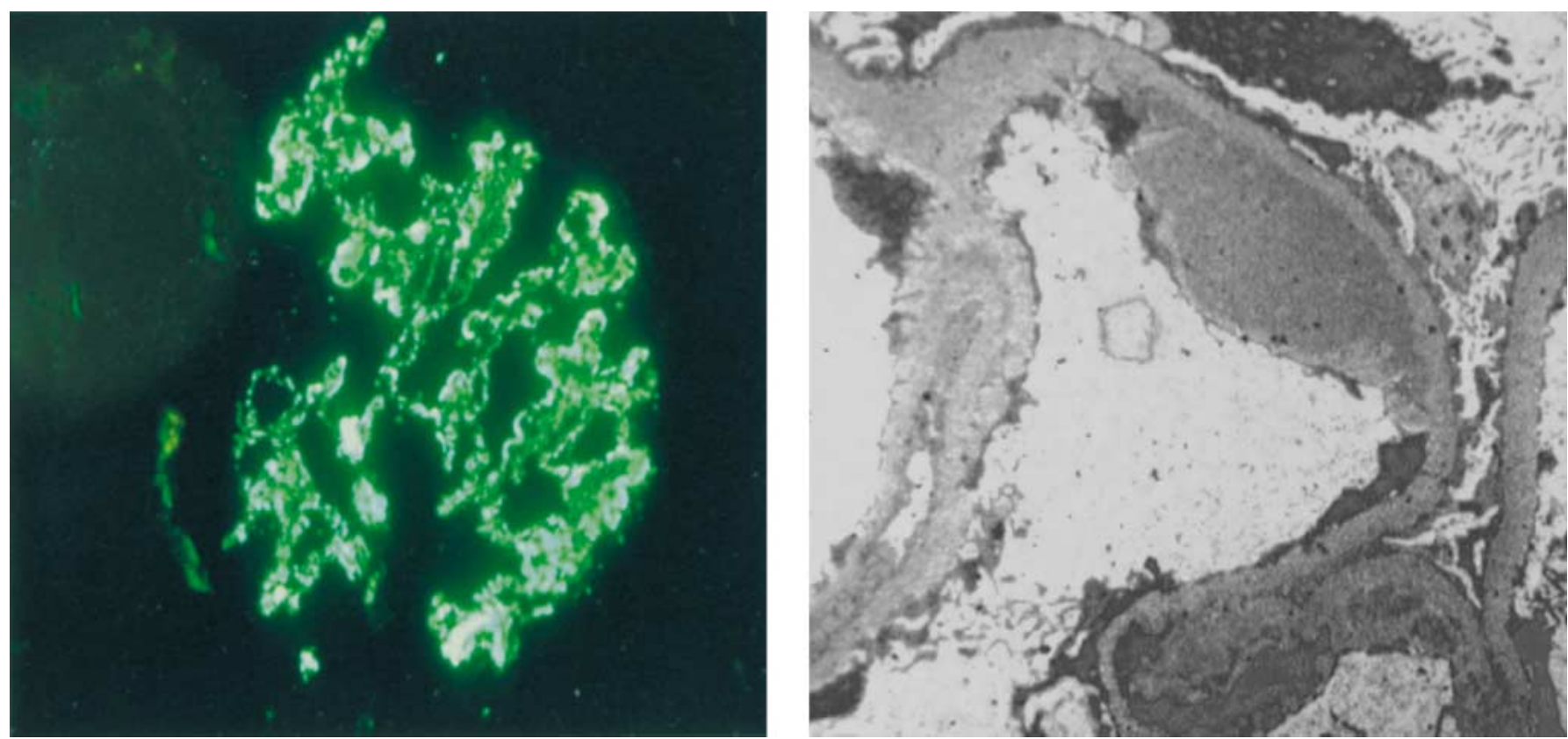

Fig. 2. Positive peripheral and granular immunofluorescence staining for $\mathrm{C} 3(2+$, left $\times 20)$. Diffuse fusion of the foot processes of the visceral epithelial cells and large subendothelial electron dense immune complex (right, transmission electron microscopy). Uranyl acetate and lead citrate. $\times 3,000$. 
exhibited segmental thickening with large sub-endothelial electron dense immune complexes easily seen (fig. 2, right).

\section{Final Diagnosis}

Recurrent focal proliferative lupus nephritis (WHO III). After the current biopsy her immunosuppressive regimen was manipulated, and she was started on cellcept instead of azathioprine. She did not accepted cyclophosphamide therapy. Her serum creatinine has been slowly increasing from 1.4 to 1.6 and up to $2.0 \mathrm{mg} / \mathrm{dl}$, during her following visits in August, October and December 2001, respectively.

\section{Discussion}

It is well recognized that lupus patients with end-stage renal disease are good candidates for renal transplantation, and that graft survival is not different from nonlupus renal transplant recipients [3]. Recurrence of lupus nephritis is unusual, and it has been estimated to be as low as $1 \%$ by some authors $[5,6]$. Additional reports indicate that the true frequency of recurrent lupus nephritis is underreported, with a more realistic rate of recurrence oscillating from $2.8 \%$ up to $8.7 \%$ [3, 7]. Some reasons for underestimating the true incidence of recurrent lupus nephritis may be the rigorous post-transplantation immunosuppressive treatment, insufficient follow-up, and empirical treatment of impaired renal allograft dysfunction interpreted as rejection episodes. An additional reason may be the fact that lupus patients with end-stage renal disease experience clinical and serological remission of their disease activity [8]. It is also known that there is no association between serologic markers of lupus and recurrent disease and that serologic markers are not reliable indicators of disease activity after transplantation [9].

The case we are reporting illustrates an additional recurrence of lupus nephritis, which interestingly oc- curred in the second allograft of a lupus transplanted patient.

The patient has lost her first allograft due to a mesangialproliferative glomerulonephritis with positive mesangial immunofluorescence staining for $\operatorname{IgG}$ and $\mathrm{C} 3$, and nonamyloid fibrillary mesangial deposits by electron microscopy. This biopsy was interpreted as de novo fibrillary glomerulopathy in the renal allograft of a lupus patient [10]. However, the possibility that the fibrillary material seen represented nonclassical immune complexes in recurrent lupus nephritis was not completely excluded. During that time the patient did show positive DsANA, low complement levels, as well as acute deterioration of her renal function. However, no clinical symptoms of SLE were present, and she lost her first allograft about 6 months later despite appropriate treatment. Retrospectively, we believe that this patient lost her first allograft due to recurrent lupus nephritis with nonclassical pathological findings in the renal biopsy. She underwent a second cadaveric renal transplantation a year later, and had a stable renal function for 5 years. She now presented with positive serologies for lupus, low complement levels, mild proteinuria and slight increase in serum creatinine. In addition, clinical symptoms including skin rash and arthralgia were also present. The current renal biopsy revealed a focal proliferative lupus nephritis (WHO III), with the expected 'full house' immunofluorescence staining pattern, and associated subendothelial immune complexes by electron microscopy. This unique case illustrates the clinico-pathologic diagnosis of recurrent focal proliferative lupus nephritis (WHO III) in the second allograft of a lupus transplanted patient.

\section{References}

1 Stone JH, Amend WJ, Criswell LA: End-stage renal disease. Lupus patients may be particularly susceptible to adverse events occurring in the first year after transplantation. Further investigation is needed to improve renal transplantation outcomes for patients with lupus. Semin Arthritis Rheum 1997;27:18-26.

2 Stone JH: End-stage renal disease in lupus: Disease activity, dialysis, and the outcome of transplantation. Lupus 1998;7:654-659.

3 Mojcik CF, Klippel JH: End-stage renal disease and systemic lupus erythematosus. Am J Med 1996;101:100-107.
4 Hariharan S, Peddi VR, Savin VJ, Johnson CP, First MR, Roza AM, Adams MB: Recurrent and de novo renal disease after renal transplantation: A report from the renal allograft disease registry. Am J Kidney Dis 1998;31:928-931.

5 Mathew TH: Recurrence of disease following renal transplantation. Am J Kidney Dis 1998; 12:85-96.

6 Ramos EL, Tisher CC: Recurrent diseases in the kidney transplant. Am J Kidney Dis 1994; 24:142-154

7 Russel R: Frequency of recurrent lupus nephritis among ninety-seven renal transplant patients during the cyclosporine era. Arthritis Rheum 1998;41:678-686.
8 Colvin RB: Heptinstall's Pathology of the Kidney: Renal Transplant Pathology. Philadelphia, Lippincott-Raven, 1998, pp 1409-1540.

9 Bumgardner GL, Mauer SM, Payne W, Dunn DL, Sutherland DE, Fryd DS, Aschner NL, Simmons RL, Najarian JS: Single-center 1-15year results of renal transplantation in patients with systemic lupus erythematosus. Transplantation 1988;46:703-709.

10 Isaac J, Herrera GA, Shihab FS: De novo fibrillary glomerulopathy in the renal allograft of a patient with systemic lupus erythematosus. Nephron 2001;87:365-368. 